\title{
“MULHER NA RODA NÃO É PRA ENFEITAR"! A GINGA FEMINISTA E AS MUDANÇAS NA TRADIÇÃO DA CAPOEIRA ANGOLA
}

\author{
Camila Maria Gomes Pinheiro ${ }^{1}$
}

\begin{abstract}
Resumo: Este trabalho apresenta um novo cenário na capoeira angola proporcionado pela participação e liderança das mulheres nos grupos. Trata-se de um fenômeno recente na história da capoeira angola: o feminismo angoleiro. Partindo de uma perspectiva feminista, pretendo apontar como os mecanismos utilizados nos discursos tradicionais que reproduzem condutas heteronormativas e classificações sexistas, estão sendo questionados e ressignificados. Para desenvolver a minha reflexão sobre esse novo cenário político apresento o grupo Nzinga de Capoeira Angola, fundado por uma mulher, mestra Janja, com sede na cidade de Salvador. Este grupo é referência para as redes de mulheres capoeiristas que estão se formando pelo mundo e desenhando uma ginga feminista. Neste aspecto, a participação das mulheres está associada à construção de outras narrativas com novos sujeitos políticos, reconstruindo as categorias "mulher" e "homem", "feminilidade" e "masculinidade", não como unidades homogêneas e isoladas. Nos Encontros de Mulheres Capoeiristas, busca-se observar novas formas de contestação e de denunciar as desigualdades de gênero presente na capoeira. No jogo da capoeira, as mulheres criam estratégias para enfrentar os obstáculos impostos por uma cultura patriarcal e hegemônica e aprendem a usar o corpo como uma arma política e de defesa pessoal para jogar na vida.
\end{abstract}

Palavras-chave: mulher; capoeira; tradição; mudança; gênero.

Abstract: This work presents a new scenario in capoeira angola provided by the participation and leadership of women in the groups. It is a recent phenomenon in the history of capoeira Angola: Angolan feminism. Starting from a feminist perspective, I intend to point out how the mechanisms used in traditional discourses that reproduce heteronormative behaviors and sexist classifications are being questioned and reframed. To develop my reflection on this new political scenario, I present the group Nzinga de Capoeira Angola, founded by a woman, master Janja, based in the city of Salvador. This group is a reference for the networks of capoeirista women who are forming around the world and drawing a feminist swing. In this respect, the participation of women is associated with the construction of other narratives with new political subjects, reconstructing the categories "woman" and "man", "femininity" and "masculinity", not as homogeneous and isolated units. In the Encounters of Capoeiristas Women, we seek to observe new forms of contestation and to denounce the gender inequalities present in capoeira. In the capoeira game, women create strategies to face the obstacles imposed by a patriarchal and hegemonic culture and learn to use the body as a political and self-defense weapon to play in life.

Keywords: woman; capoeira; tradition; change; gender.

\footnotetext{
${ }^{1}$ Doutorado em Ciências Sociais pela Universidade Federal do Rio grande do Norte (UFRN), orientada pela Prof $^{\mathrm{a}} \mathrm{Dr}^{\mathrm{a}}$ Julie Cavignac (PPGA-PPGCS-UFRN). E-mail: camilaufpb@yahoo.com.br. ORCID:
} https://orcid.org/0000-0003-4807-8096. 


\section{Introdução}

Se aventurar nos caminhos abertos pelas mulheres no universo da capoeira na contemporaneidade é um desafio instigante. Ainda mais porque esta manifestação cultural vem assumindo novas feições e passando por mudanças radicais, sobretudo a partir da ocupação das mulheres nos espaços de poder. Assistimos ao crescente número de mulheres praticando capoeira, o que ainda não corresponde, proporcionalmente, à atuação destas nas lideranças dos grupos. O desenvolvimento de uma ginga feminista vem desmontando as imagens e representações das mulheres na tradição da capoeira angola. Desse modo, essa pesquisa se debruça sobre a constituição e a disseminação de um fenômeno recente na capoeira angola, o feminismo angoleiro. A minha proposta é analisar a constituição de uma ginga feminista e como esta vem causando impactos na capoeira angola.

A amplitude das pautas do movimento feminista tem adentrado espaços até então considerados rígidos e intransponíveis, e isso tem causado inúmeros impactos nas estruturas tradicionais de dominação masculina na capoeira angola. Muitos questionamentos vieram à tona; no entanto, um aspecto é fundamental para a discussão que pretendo desenvolver neste texto: qual o lugar que a mulher ocupa na tradicional capoeira angola? O que acontece quando as mulheres entram na roda e ocupam os espaços de poder? Como a tradição da capoeira angola se ressignifica com a liderança das mulheres na organização dos grupos? O que acontece na capoeira quando elas tomam a ginga feminista como conhecimento?

O feminismo angoleiro surge dentro do movimento de mulheres capoeiristas no qual há uma incorporação das lutas feministas no universo da capoeira, fazendo conexões entre a pequena roda, onde o jogo da capoeira acontece, e a grande roda, que simula a roda da vida.

Para refletir sobre estas questões, a pesquisa se debruça sobre o Grupo N'zinga de Capoeira Angola, localizado na cidade de Salvador, na comunidade Alto da Sereia. O grupo apresenta um diferencial no mundo da capoeira, pois foi fundado por uma mulher na década de 1990, pela Mestra Janja ${ }^{2}$, posteriormente somaram ao grupo a mestra Paulinha ${ }^{3}$ e o mestre Poloca ${ }^{4}$. Este grupo se tornou uma referência para pensar a construção das mulheres como

\footnotetext{
2 Rosângela Araújo é mestra de capoeira e professora universitária do Departamento de Estudos de Gênero e Feminismo da Faculdade de Filosofia e Ciências Humanas da Universidade Federal da Bahia/UFBA. Graduada em História pela Universidade Federal da Bahia/UFBA, possui Mestrado e Doutorado em Educação pela Universidade de São Paulo/USP. É Líder do Grupo de Pesquisa (CNPq) Núcleo de Estudos Interdisciplinares sobre a Mulher/NEIM (UFBA) e pesquisadora do A Cor da Bahia.

3 Paula Barreto é professora adjunta do departamento de Sociologia na UFBA e mestra no grupo Nzinga.

4 Paulo Barreto é geógrafo e arte-educador. É mestre no grupo N’zinga.
} 
sujeitos políticos, conscientes de sua condição e nas estratégias de combates contra as formas de opressão de raça, sexo e classe.

O grupo está presente em outras cidades brasileiras como Brasília, São Paulo, Rio de Janeiro, assim como em outros países como México, Moçambique, Japão, Maputo, Alemanha. As Atividades desenvolvidas dentro e fora do grupo traduzem um modo diferenciado de organização social no campo da cultura popular. Escolhi esse grupo para tentar compreender como a ocupação das mulheres nas práticas e nas lideranças do grupo tem provocado mudanças nas formas de organização, dando novos significados à tradição da capoeira angola. Nesta pesquisa, apresento o novo cenário na capoeira angola proporcionado pela participação e liderança das mulheres nos grupos.

Verifiquei que os estudos sobre cultura popular pouco abordam as desigualdades sociais, as discriminações raciais e sexistas, e suas reproduções nos grupos. Compartilhar com outras mulheres sobre as inúmeras formas invisíveis de violência e opressão presentes, dentro e fora da roda de capoeira, fez-me perceber a relevância de investigar esse tema academicamente.

Depois de alguns anos participando de eventos organizados por mulheres de orientação feminista, os depoimentos compartilhados relatavam algumas situações semelhantes de violência, ainda vigorantes (dentro e fora) da roda de capoeira. Essa realidade me fez perceber a relevância de investigar esse tema da mulher na capoeira mais profundamente. Neste aspecto, chamo atenção para o patriarcado como elemento central e comum, formador da tradição da cultura brasileira que acompanha, concomitante, a constituição de uma tradição para a capoeira. A atuação das mulheres tem transformado e confrontado a concepção engessada e hegemônica de tradição, colocando em cheque a permanência de uma verdade que se torna absoluta e que dita a ética do capoeirista.

\section{Oh Aidê, Aidê cadê você: a invizibilização da mulher na tradição da capoeira angola}

As mulheres não são passivas nem submissas. Elas estão presentes aqui e além. Elas são diferentes. Elas se afirmam por outras palavras, outros gestos. $\mathrm{Na}$ cidade, na própria fábrica, elas têm outras práticas cotidianas, formas concretas de resistência à hierarquia, à disciplina, que derrotam a racionalidade do poder, enxertadas sobre seu uso próprio do tempo e do espaço. Elas traçam um caminho que é preciso reencontrar. Uma história outra. Uma outra história. (Michelle Perrot, 1928).

Para iniciar a discussão, eu pretendo levar o leitor a revisitar narrativas no imaginário da capoeira angola, e desvendar um lugar até um tempo atrás pouco falado, não reconhecido 
por muitos capoeiristas, principalmente pela condição de silenciamento que lhe foi imposta: trata-se do lugar das mulheres na tradição. Ao me questionar sobre o papel que as mulheres ocupam na construção das narrativas sobre a capoeira angola, me deparei com as ausências nos dizeres sobre a atuação das mesmas na manutenção de uma tradição para a capoeira. A busca desse lugar revelou lacunas e foi mergulhando nelas que conheci melhor a existência de algumas "estórias" e "histórias" que não são contadas. Esse caminho direcionou o meu olhar para as ausências, conduziu a minha ginga para além das "presenças" que não tem destaque nas memórias, pois aguçou uma reflexão sobre como esse espaço da tradição tornouse masculinizado.

Em muitos momentos, enquanto ouvia atentamente às histórias contadas pelos mestres, ou até mesmo nas rodas de conversas, onde essas mesmas histórias eram recontadas e transmitidas como verdades, perguntei-me onde estavam as mulheres nessa narrativa. Não me conformava o fato de estarmos apenas na condição de artefato, enfeite, objeto disputado para consumo, no papel de figurantes, ou como apenas ouvintes daquela verdade que se conta ainda hoje. Será que não havia espaço para elas na história da capoeira?

Foi buscando conhecer as vozes das mulheres na tradição da capoeira que percebi que elas são invizibilizadas pelos discursos produzidos e reproduzidos pelos homens. Comecei a revisitar as imagens históricas da capoeira, trechos de vídeos e documentário antigos, e questionar qual o lugar das mulheres nas narrativas construídas sobre a capoeira no Brasil. Quis saber sobre aquelas imagens onde geralmente estão presentes mulheres de terreiro nas rodas de capoeira, sobre as músicas que falavam sobre as mulheres. Pensei logo: Será que as mulheres jogavam uma outra capoeira?

Christiane Zonzon (2017) afirma que sim. Em seu livro recentemente lançado denominado 'Nas rodas da capoeira e da vida: corpo, experiência e tradição', a autora afirma que "pelo fato das mulheres, ainda, não participarem plenamente das rodas de rua, elas incorporam a capoeira através de outro currículo, ou talvez jogam outra capoeira” (p. 302). Nessa obra, Zonzon (Idem) fornece uma abordagem sobre o processo de formação do/a capoeirista pela experiencia corporal e o universo da tradição em que se realiza e aprende a prática da capoeira.

Maria José Somerlate Barbosa, professora de literatura e cultura brasileira na Universidade de Iowa (EUA) tem um trabalho ${ }^{5}$ sobre a mulher na capoeira no qual evidencia o silenciamento das mulheres nos discursos sobre a capoeira. Somerlate (2005), afirma que

5 Artigo intitulado "A mulher na capoeira" publicado no Arizona Journal of Hispanic Cultural Studies, volume 9, 2005, pp.9-28. 
“as referências às mulheres são esparsas e de pouco vulto e não há uma análise sistemática da sua participação ativa nos círculos de capoeira" (p.12). O estudo feito por Somerlate (Idem) é muito relevante, pois traça a trajetória da mulher na capoeira com enfoque nas mudanças dos últimos anos e os elementos que permitem uma atuação mais significativa nos espaços onde a capoeira se manifesta: nas rodas, academias e agremiações. Ela ainda ressalta as principais atividades e as contribuições femininas para divulgação da capoeira no Brasil e nos Estados Unidos, sem deixar de elencar as dificuldades que a mulher ainda enfrenta.

Poucos pesquisadores e mestres fazem referência às mulheres nos livros sobre a história da capoeira. Poucos são os nomes de mulheres citados, como Maria Doze Homem, Maria Felipa, Julia Fogareira, Adelaide Presepeira, Angélica Endiabrada - entre outras. Além disso, quando fazem referência à atuação das mulheres, o que sobressai em primeiro plano é a atribuição dessas a um suposto "comportamento masculino". Expressões do tipo "jogava como homem" ou até mesmo o próprio apelido "doze homens" já demonstrava esse apagamento da condição de mulher. Somerlate (2005) destaca:

Parece importante também ressaltar que a documentação escrita é extremamente escassa para que se possa traçar um perfil e/ou avaliar com precisão o desempenho feminino no âmbito da capoeira nas décadas anteriores a 1970. Seria arriscado e impróprio tanto simplificar a contribuição feminina, reduzindo-a a umas poucas capoeiristas, como assegurar que um número significativo de mulheres tenha participado ativamente das rodas ou do jogo antes dos anos 70 , pois não há suficiente documentação escrita para que se estabeleça qualquer um dos dois argumentos (p. 10).

Para uma melhor compreensão desta problemática, eu procurei buscar o depoimento de mulheres capoeiristas que estão participando ativamente desse debate, não apenas na condição de liderança no campo da capoeira, mas também na condição de pesquisadora do tema como Rosangela Araújo, que além de ser mestra de capoeira angola, é também professora universitária e uma importante e reconhecida pesquisadora do campo da capoeira. A mestra e pesquisadora, introduz esse debate na capoeira:

Esse fenômeno da mulher na capoeira é relativamente recente e tanto a capoeira angola como a capoeira regional têm suas próprias tradições e essas tradições foram alimentadas e transmitidas por várias gerações através dos homens. Isto tem imposto à capoeira um olhar que é masculino, uma estética que é masculina e um entendimento que é masculino. Muitas vezes nas estruturas de liderança a autoridade é confundida com autoritarismos e as mulheres não encontram espaços para falarem ou se expressarem dentro dos grupos. Quando o fazem são tratadas por "fofoqueiras" e apontadas como quem "fala demais" (ABREU; CASTRO, 2009, p. 204). 
Durante a minha trajetória na capoeira percebi a persistência da centralidade do olhar masculino de que fala Janja, por parte de alguns mestres e grupos, na manutenção de algumas regras de conduta, nos modos de agir nos treinos e nas rodas de capoeira, nas músicas cantadas no jogo que desqualificam e reproduzem as desigualdades de gênero. Isso é verificável tanto nas falas e ações dos mestres como na própria forma como a tradição é entendida na capoeira, ainda priorizando o modelo patriarcal (o poder centralizado no mestre). O Mestre Canjiquinha ${ }^{6}$, foi um importante e reconhecido mestre de capoeira angola, e partilha de um posicionamento tradicionalista, reforçando um olhar sexista para a capoeira. Com medo da mudança, do novo, de que a capoeira possa um dia se acabar ele afirma que "a capoeira está morrendo virou apenas dança para turista ver" (ABREU; CASTRO, 2009, p. 40). Ele diz que os mestres, hoje em dia, são poucos e tendem a desaparecer. Queixa-se da falta de divulgação da capoeira que, em seu entendimento, deveria ser transformada em esporte nacional (Ibid.).

Um exemplo deste tipo de visão tradicionalista da capoeira pode ser observada na forma como o mestre canjiquinha fala sobre a participação das mulheres na capoeira: "Mas mulher, as únicas mesmo foram Maria Doze Homens que numa briga da saúde até o antigo Cinema Olímpia, bateu em doze marmanjos, e Maria Palmeirão, 1,90 de altura, mulher de dar e receber navalhada, seca como diabo que lutava como homem" (grifo nosso). A concepção do mestre, mantém de forma clara, o olhar comparativo entre mulher e homem, centralizando na figura do homem o parâmetro para considerar uma mulher como boa capoeirista. No entendimento do mestre, as duas mulheres só são destacadas porque conseguem ser comparadas aos homens; neste caso citado pelo mestre canjiquinha, ao bater em doze marmanjos ou porque lutava como homem.

É importante trazer esses entendimentos sobre a atuação das mulheres na capoeira para que narrativas que rebaixam, silenciam e reproduzem as desigualdades de gênero sejam refletidas e ressignificadas. Outro ponto a destacar sobre as formas de rebaixamento da mulher se encontra presente nesta frase sobre o entendimento da capoeira, onde o mestre afirma "[...] e ainda existe quem a considere agressiva: meu deus querem afeminar a luta dos homens" (ABREU; CASTRO, 2009, p. 43).

$\mathrm{Na}$ visão do mestre, querer afeminar a capoeira é transformá-la em "dança" ou retirarlhe o caráter de luta. Fica claro, nesse depoimento, um tipo de percepção de mundo limitada,

6 Washington Bruno da Silva. Entrevista de Cristina Cardoso, publicada originalmente em diários de noticias de salvador, em 06 de setembro de 1970. É um dos capoeiristas mais conhecido no mundo, participou de filmes como Barravento de Glauber Rocha, e o pagador de promessas de Anselmo Duarte. 
que insiste em associar a feminilidade ao que é frágil, dócil, passivo, sensível. Essa forma de encarar a capoeira é problemática, na medida em que são naturalizadas as diversas formas de discriminação e violência contra a mulher, e contra qualquer forma de identidade de gênero que não esteja dentro dos padrões heteronormativos. Lembrando que ocultar, silenciar e criar meios de invisibilização das mulheres na capoeira são algumas das formas mais recorrentes de violência contra a mulher e se manifesta nas rodas, encontros e eventos de capoeira.

Nos poucos estudos sobre a participação das mulheres na capoeira, Oliveira e Leal (2009), em sua obra 'Capoeira, identidade e gênero', afirma que a rua não era apenas para os homens e a valentia não era característica masculina:

Nas páginas dos principais jornais de Salvador, durante as três primeiras décadas republicanas, não são poucos os casos que envolvem mulheres, entre estes, aqueles em que elas são protagonistas da cena. $\mathrm{O}$ ato de valentia não estava restrito ao universo masculino. Era um valor atribuído a mulheres e homens, atores que constituíam o cotidiano das ruas da civilizada cidade da belle epoque baiana (p. 123).

O processo recente de ocupação das mulheres nos espaços de poder, como organização e liderança dos grupos, tem provocado impactos significativos na tradição da capoeira angola. Tendo em vista que estas mulheres estão transformando os espaços de silenciamento em lugar de fala. É neste aspecto que a minha investigação ganha fôlego: as mudanças e os impactos decorrentes da organização das mulheres, como sujeito político, protagonistas de suas histórias, refazendo as narrativas, reconstruindo seus espaços e ressignificando a tradição. A partir destas ações podemos afirmar que está se configurando uma nova ginga na tradição da capoeira angola. De acordo com Rosângela Araújo, a Mestra Janja em uma entrevista ao historiador Frederico José de Abreu, podemos perceber a mudança em vários aspectos:

Começamos a mudar o próprio espaço da roda como um espaço para evidenciar as formas como essas violências se manifestavam e que maneira era mais evidenciada, começamos a fazer eventos e a discutir sobre esses assuntos. Nunca fizemos eventos exclusivos só de mulheres, mas sempre com a participação de homens, por acreditarmos que na medida que as mulheres se fortalecem, o grupo se fortalece junto. A medida que as mulheres se fortalecem, a capoeira também se fortalece (ABREU; CASTRO, 2009, p. 202).

O que está se contestando são os modos como os elementos estão sendo apropriados pelos mestres e sendo transformados em regras e valores para atuarem na tradição da capoeira. Os discursos são reelaborados para agirem como uma norma que se eterniza na prática, se afirmam como verdades absolutas na construção de narrativas e, desse modo, devem ser oficializados nos grupos. 
Para situarmos a história das mulheres na capoeira é necessário situar a capoeira dentro de um campo mais amplo na história das mulheres. Teremos que traçar o percurso que as mulheres trilharam para conseguir um espaço nas sociedades contemporâneas. A fala do mestre Pastinha, em entrevista ${ }^{7}$ a Roberto Freire $^{8}$, apresenta uma narrativa mítica sobre a origem ancestral da capoeira onde a mulher é idealizada como um prêmio para o vencedor da luta:

Diz que em angola, há muito tempo, séculos mesmo, fazia-se uma festa todo ano em homenagem às meninas que ficavam moças. Primeiro elas eram operadas pelos sacerdotes, ficando igual, assim com as mulheres casadas. Depois enquanto o povo cantava, os homens lutavam do jeito que fazem as zebras, dando marradas e coices. Os vencedores tinham como prêmio escolher as moças mais bonitas entre as operadas. Pode não ser verdade, mas os capoeiristas de hoje bem gostariam eu fosse, desde que suas vitórias tivessem prêmio igual... (SCALDAFERRI, 2009, p. 28).

Deve-se olhar para a história e o lugar destinado às mulheres, assim como, analisar como estão sendo rompidas as desigualdades de gênero. As mulheres estão deixando de estar na condição de subjugadas e subordinadas, e passando a escolher o lugar que desejam ocupar, inclusive liderando grupos, questionando as limitações da tradição e desenhando uma nova ginga pelo mundo. Para Rosângela Araújo, mestra Janja, a mudança começa na reflexão sobre o reconhecimento da mulher como um sujeito que pensa, que sente, que age e que transforma o mundo e a capoeira. Ela afirma:

Hoje temos a necessidade de falar sobre o que é ser, de fato, mestre de mulheres pois a mulher traz para a roda seu próprio universo e sua vida de mulher. O mais interessante é reconhecer que as mudanças sociais que a gente almeja se fazem também com lideranças de mulheres. Passamos a reconhecer que esse é um momento diferenciado na história da capoeira (ABREU; CASTRO, 2009, p. 202-203).

Quando se isola a capoeira do contexto histórico corre-se o risco de não reconhecer seu caráter da resistência. É importante ressaltar o caráter de negociação da capoeira com a sociedade. O fato de estar presente no mundo todo é uma forma de resistir; no entanto, se colocarmos a sua tradição e sua história em um lugar de pureza, e a essencializarmos, não relacionando-a com as transformações do mundo externo, como se pode pensar a resistência? Se a capoeira e a sua tradição não podem sofrer mudanças, como podemos pensar a resistência?

7 Entrevista realizada por Roberto Freire e publicada na revista realidade, 1967.

8 Foi médico psiquiatra, escritor, jornalista. Conhecido por desenvolver uma técnica terapêutica somaterapia baseada nas idéias anarquistas de Wilhelm Reich. 
As mudanças na tradição são provenientes da atuação de algumas mulheres nos espaços poder, liderando os grupos e assumindo o seu lugar nos discursos. A atuação dessas "mulheres" tem provocado tensões nas estruturas dominantes da capoeira. O que chamo de estruturas dominantes são as formas enrijecidas, onde discursos e práticas, combinados, contribuem para a reprodução das desigualdades de gêneros como naturais. O que é percebido é que nem todas as mulheres que lideram grupos, ou estão em posição de poder dentro da estrutura hierárquica da capoeira, têm posicionamentos políticos e críticos sobre as discriminações e desigualdade de gênero na capoeira.

Hoje, o número de mulheres praticando capoeira já está equiparado ao de homens, e em alguns lugares e grupos, as mulheres chegam a ser maioria. Porém, ainda há uma disparidade em relação a ocupação das mulheres nos espaços de liderança, exercendo a mestria. É sobre essas mudanças na configuração política da capoeira que este trabalho se sustenta.

No Brasil, a ampliação das discussões feministas, juntamente e paradoxalmente com os crescentes ataques aos direitos da mulher. tem atraído muitas mulheres para a capoeira. Embora tenha me referido ao Brasil, como caso específico, o aumento na quantidade de mulheres praticando capoeira é um fenômeno mundial. Esse processo que fortalece as redes sociais conectadas no globo e está possibilitando desconstruções e reconstruções relacionadas ao discurso da tradição.

\section{O grupo Nzinga e a ginga fesminista: ressignificação da tradição}

A escolha do nome Nzinga pelas mestras significa uma afirmação identitária, no sentido de chamar atenção para o lugar da mulher na capoeira. A fala da mestra Paulinha sobre a escolha do nome do grupo, demonstra a intenção de marcar e valorizar o lugar da mulher na capoeira:

Nós escolhemos esse nome grupo Nzinga de capoeira angola para homenagear uma mulher, guerreira africana, né?! Marcar esse lugar de protagonista da mulher e desde então o grupo teve continuidade, sempre marca através de discussões, reflexões o lugar da mulher na capoeira. Nós somos sempre convidadas a participar de conferências só de mulheres ou voltadas para a questão feminina e consolidamos esse trabalho lá. Depois eu mais Poloca retornamos a Salvador aí abrimos o núcleo aqui, aí o grupo foi se expandindo?.

9 Fala da mestra Paulinha no vídeo Malungos 30 anos. https://www.youtube.com/watch?v=ltwuLEZvCUo. Acesso em: 30 mai. 2016. 
Desse modo podemos perceber como a reconstrução da tradição se efetiva a partir da liderança das mulheres no mundo da capoeira. As Mestras Janja e Paulinha afirmam com veemência que a definição do nome está relacionada com uma reconstrução de narrativa que direciona o olhar para a condição das mulheres na capoeira, conforme assinala em entrevista:

A gente então resolve dar o nome de Nzinga Mbandi Ngola que é a soberana do endome de Matamba e também sendo esta uma forma de homenagear e chamar atenção para a presença das mulheres na capoeira, que hoje constituem em média de $35 \%$ a $40 \%$ dos praticantes de capoeira de um modo geral, mas que isso não reverbera em ocupação dos espaços de poder e de liderança ${ }^{10}$.

Na Bahia, Janja, Poloca e Paulinha conviveram diretamente com mestres renomados da capoeira angola como mestre João Grande, mestre Moraes, Mestre Cobra Mansa, entre outros. Janja reconhece a importância de Paulinha e Poloca na cidade de São Paulo na formação do grupo: "a vinda e permanência por alguns anos dos mestres baianos Poloca e Paulinha em São Paulo (e por razões semelhantes) foi fundamental para o fortalecimento e definições institucionais, resultando também no surgimento do núcleo de Salvador (ARAÚJO, 2005, p. 7). Atualmente, soma-se à liderança no grupo Nzinga, o mestre Peter, que iniciou sua trajetória em 1995, quando Janja e Paulinha estavam na capital paulista. No ano de 2005 foi consagrado como treinel durante o evento de 10 anos do grupo, assumindo o núcleo do grupo no bairro do Tucuruvi localizado na zona norte de São Paulo.

O grupo Nzinga segue a linhagem de seu maior expoente, o mestre Pastinha, sendo a preocupação do grupo centrada na valorização e preservação dos valores que regem a capoeira angola.

A experiência de Pastinha nos legou a recuperação dos valores agrupados pela ludicidade, teatralidade e religiosidade na capoeira angola, alicerçar a atuação da maioria dos seus antecedentes estruturando aspectos ritualísticos que nos permitem pensar o seu entendimento sobre a ética de uma práxis educativa voltada à formação do grupo e ao fortalecimento da sua identidade (ARAUJO, 2005, p. 13).

Para apresentar melhor a formação do grupo, deixarei que a mestra Janja nos explique como se deu esse processo de formação e a importância das pessoas para a consolidação do grupo, levando em consideração a liderança compartilhada entre os mestres Poloca e a mestra Paulinha:

Também acrescentarei mais algumas pessoas além da mestra Paulinha e do mestre Poloca, e o mestre Tião Carvalho, mestre da cultura tradicional maranhense. E na realidade esse grupo nasce aqui em São Paulo por incrível que pareça, eu sou baiana mas meu grupo surge em São Paulo. Eu venho de 
Salvador para estudar aqui, eu vim fazer a pos graduação. La na Bahia eu já estava num grupo de capoeira angola (...) eu já havia mudado para aqui e trazia uma tradição de uma escola de capoeira muito reconhecida, é o GCAP e os mestres João Grande, Moraes e Cobra mansa. Então, quando eu vim pra cá eu já estava inserida numa vivência que tomava a capoeira como um instrumento político de luta. Nós éramos já um grupo inserido num contexto do ativismo pela justiça social [...]. Portanto a gente começa aqui em São Paulo um trabalho e exatamente por ser uma novidade no mundo da capoeira, uma mulher está a frente da organização da criação de uma organização de capoeira ${ }^{11}$.

O Nzinga destaca-se na cena, principalmente, pelo modo como a tradição é trabalhada dentro do grupo, trazendo para a pequena roda as demandas das pautas do feminismo negro e o que elas representam: a demarcação das mulheres como sujeitos políticos na capoeira e a construção de uma tradição voltada para práticas antissexistas e antirracistas.

Gostaria de elencar que um dos pontos que merecem ser destacados ao se falar sobre a ressignificação da tradição pelo Nzinga está relacionado ao modo como é trabalhada a religiosidade no grupo. A ligação marcante do Nzinga com o candomblé fortalece o discurso da ancestralidade, trazendo para a roda de capoeira formas de organização onde as mulheres encontram-se em uma posição de destaque, pois são detentoras de um poder para além da matéria, que atravessa a kalunga, linha que separa os dois mundos espiritual e material.

A religiosidade marcante no Nzinga e celebrada durante a festa de Iemanjá tem demonstrado uma nova forma de entender a ancestralidade no universo da capoeira. Para a maioria dos grupos de capoeira angola no Brasil, a ancestralidade é conhecida e reverenciada a partir de construções de figuras masculinas como, por exemplo, Zumbi. Como contraponto, no Nzinga observei que a ancestralidade é um fator elementar no fortalecimento do poder para as mulheres, de modo que traz para a roda a formação de uma tradição reconstruída através das narrativas de personagens femininas como Iemanjá e a rainha Nzinga.

\section{A mulher entrou no jogo: por um feminismo angoleiro}

Mulher tem que provar a competência através da força. E como lidar com o outro? Nesse aspecto entendo que a perspectiva do nzinga é trabalhar com a diferença. Questiona-se o problema do ser "feminino", pensar a mulher na capoeira mas avançar no debate e na discussão em relação a pluralidade de mulheres. Não se fala de um tipo de mulher mas de

11 Entrevista realizada pelo programa Conectad@s , gravado no Centro Cultural de São Paulo no dia 14/11/2017 com a participação da mestra janja e Instituto Nzinga. A entrevista foi realizada por Priscila Fenix, rapper que conheceu mestra Janja em Salvador no ano de 2016 no VI Chamada de Mulher. 
uma diversidade, idosa, com ou sem deficiência física, mental, gorda, magra, preta, branca, mãe, solteira, filha.

A heteronormatividade e o sexismo utilizados por muitos mestre e grupos como regra justificável para as inúmeras situações de discriminação e silenciamento, colocam as mulheres como prisioneiras da tradição. Essas "grades" não aprisionam os homens. No entanto, as correntes são quebradas a partir do enfrentamento de obstáculos pelas mulheres, como a saída delas do espaço privado para o lugar público. Quando a mulher escolhe ir para a capoeira, ela afirma seu poder de decisão. Neste aspecto, mestra Janja, atesta que "qualquer processo que passe pelo corpo e que reflita na corporeidade, na construção da liberdade e da dignidade é um processo de empoderamento.”(mestra Janja em enrevista a Pulsar, julho, 2016).

No Brasil o número de mulheres que praticam vem crescendo porém essa realidade ainda não se estendem às lideranças dos grupos de capoeira. Partindo desse entendimento, esta pesquisa analisa a trajetória de mulheres que iniciaram o processo de mudanças na concepção da "tradição" da capoeira angola. A dinâmica em torno do conceito de tradição é observada na prática e na reconstrução de discursos. A roda de capoeira, forma simbólica e expressiva do jogo da capoeira, lugar onde o rito acontece é também o espaço onde é possível ver, ouvir e sentir o impacto da mudança. Seja na postura da mulher na roda, seja no que se diz e o que se espera da mulher, tanto dentro roda de capoeira como na roda da vida. As mudanças se iniciam principalmente, no diálogo com o outro, regra básica para o entendimento do jogo da capoeira.

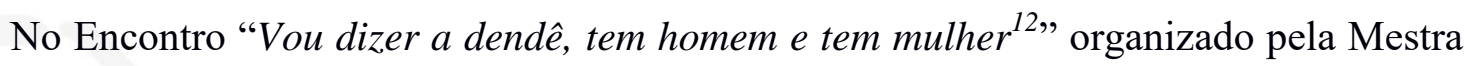
Di de Olinda-Pe, a roda inicialmente começa com a bateria ${ }^{13}$ toda formada por mulheres. Todos os instrumentos necessário na roda de capoeira como atabaque, agogô, pandeiro, recoreco, três Berimbaus (Gunga, médio, viola) são tocados por mulheres, é uma tradição que está se consolidando nos eventos de mulheres.

Outro ponto importante que tem mudado a realidade de muitos grupos com a presença das mulheres está na participação das crianças junto com suas mães. O convívio com as crianças e com as mães permite reconhecer na capoeira um espaço de acolhimento e um ambiente de coletividade. Ao levar o/a filho/a para a capoeira, a mãe tece uma ruptura com a visão tradicional de "maternidade", ela vai enfrentar o espaço público, vai sair de sua casa para ir treinar, esse deslocamento não era comum às mulheres grávidas e que ainda

12 Evento produzido pela mestra Di, Olinda-PE. Foi realizado nos dias 24, 25 e 26 de março, em Olinda, no ano de 2017.

13 É como os capoeiristas definem lugar onde estão os instrumentos. Em muitos grupos a bateria é formada por: reco-reco, agogô, dois pandeiros, atabaque e três berimbaus. 
amamentam suas crias. Levar a criança para os treinos é uma questão de autonomia das mulheres que acarreta uma serie de mudanças significativas na base do grupo.

A mudança está no fato de que agora as mulheres escolhem treinar e levar seus filhos para a capoeira. Praticar capoeira numa sociedade patriarcal é se opor às regras de comportamento impostas às mulheres, que as impossibilitam de ser livres. A capoeira faz com que ela conheça seu próprio corpo e aprenda a usá-lo como arma de defesa.

Nesse sentido os espaços estão sendo reconstruídos, e em conjunto. Quando se aprende a lidar com o outro, tem-se uma compreensão de convívio com as diferenças Nesse aspecto entendo que a perspectiva do nzinga é trabalhar com a diferença. De acordo com a mestra Janja, no feminismo angoleiro,

a primeira coisa que ele situa é a capoeira, que não posso deixar de lembrar que ela é anterior ao próprio feminismo. É também pensar o feminismo a partir de novas epistemologias e aí eu to me referindo a capoeira como um campo. Como uma epistemologia, né? E que como tal ela vai me ensinar a estar no mundo pensando essas relações de uma maneira diferenciada, ou seja, eu estou pensando essas relações como capoeirista. ( Mestra Janja, em entrevista a Pulsar, julho, 2016).

A participação das mulheres está associada à construção de outras narrativas com novos sujeitos políticos, reconstruindo as categorias "mulher" e "homem", "feminilidade" e "masculinidade", não como unidades homogêneas e isoladas. Mestra Janja, afirma que o feminismo angoleiro é uma possibilidade de reestruturação, identificação e re-identificação social. Refletir sobre a contribuição dessa prática política é justamente pensar em um feminismo que agregue, como a formação de coletivos entre pessoas, sem binarismos e sexismos, que não isole as mulheres. É uma proposta de feminismo feito junto, com homens e outros sujeitos que não se reconhecem e nem se identificam nos papéis padronizados socialmente e estabelecidos para os comportamentos de ser masculino e ser feminino.

Pensar a importância desses eventos (oficinas, encontros, vivencias, festivais) liderados e organizados pelas mulheres, para a mudança na tradição da capoeira, é um dos focos centrais desta pesquisa. Os encontros de mulheres vêm se fortalecendo ao longo dos anos. A mestra Di reconhece como foi importante e significativo participar de um evento na década de 80. Ela diz "depois de um encontro de mulheres que aconteceu no Rio de Janeiro, foi que eu senti aquele estralo.” Nesse encontro, a mestra Janja estava presente foi quando elas se conheceram.

Os eventos realizados pelo Nzinga tem uma proposta muito interessante de debates e com discussões sobre mulher, feminismo, negritude, religião, corpo, dança isto demonstra uma preocupação com a formação dos alunos do grupo. Segundo o um integrante do Nzinga, 
a proposta dos eventos é criar rodas de conversas e estimular os alunos a pesquisar, estudar e a debater. Essa forma de estruturação de eventos, que permite estimular as rodas de conversas tem sido adotado por outros grupos e coletivos de capoeiristas, não apenas de mulheres.

Pensando nas estratégias de enfrentamento, para mestra Janja, o primeiro passo é identificar como o machismo se manifesta na capoeira. Precisamos identificar as diversas formas como ele se apresenta e principalmente como ele está se reproduzindo. A principal preocupação dessa relação é denunciar o sexismo. E destacar a importância das organizações coletivas e perceber como esses grupos tem provocado impacto na estrutura patriarcal da capoeira.

\section{Referências bibliográficas}

ABIB, Pedro Rolpho Jungers. Capoeira Angola: cultura popular e o jogo dos saberes na roda. Campinas/SP: UNICAMP/CMU; Salvador: EDUFBA, 2004.

ABREU, Frederico José de; CASTRO, Mauricio Barros de (Org.). Encontros Capoeira. Rio de Janeiro: Beco do Azougue, 2009.

ABREU, Frederico José de. O barracão do Mestre Waldemar. Salvador: Zabaratana, 2003.

ARAÚJO, Rosângela Costa. Iê, Viva Meu Mestre! A Capoeira Angola da 'escola pastiniana' como práxis educativa. Tese de Doutorado apresentada ao Programa de Pós-Graduação da Faculdade de Educação da Universidade de São Paulo. São Paulo: USP, 2004. Disponível em http://www.teses.usp.br/teses/disponiveis/48/48134/tde-12052015-143733/pt-br.php. Acesso em: 28 jun. 2016.

Entrevista. Revista Toques d'Angola, Salvador, INCAB, n. 4, nov. 2005.

É preta, Kalunga: a capoeira angola como prática política entre os baianos: anos 8090. Ilustração de André Flauzino. Coleção Capoeira Viva, 2. Rio de Janeiro: MC\&G, 2015.

BEAUVOIR, Simone. O Segundo Sexo. Rio de Janeiro: Nova Fronteira, 2009.

BUTLER, Judith P. Problemas de gênero: feminismo e subversão da identidade. Tradução de Renato Aguiar. Rio de Janeiro: Editora Civilização Brasileira, 2003.

BRITO, Celso de. A regulação da instanciação religiosa na capoeira angola globalizada: A relação entre o Grupo Irmâos Guerreiros e o Ilê Obá Silekê de Berlim, Alemanha. Trabalho apresentado na 30 Reunião Brasileira de Antropologia, realizada entre os dias 03 e 06 de agosto de 2016, João Pessoa/PB.

CASTRO, Mauricio Barros. Na roda do Mundo: Mestre João Grande entre a Bahia e Nova York. Tese de Doutorado. Universidade de São Paulo (USP). Faculdade de Filosofia, Letras e Ciências Humanas. São Paulo: USP, 2007.

DAVIS, Angela. Mulheres, Raça e Classe. 1a ed. São Paulo: Boitempo, 2016.

FREYRE, Gilberto. Casa-grande \& senzala. 51 ${ }^{\mathrm{a}}$ ed. São Paulo: Global, 2006.

FRIEDAN, Betty. Mística feminina. Petrópolis: Vozes, 1971.

FOLTRAN, P. "Capoeira é pra homem, menino e mulher": angoleiras entre a colonialidade e a descolonização. São Paulo, 2017, Sankofa, 10(19), 83-106.

. A interpretação das culturas. Rio de Janeiro: LTC, 1989.

GILROY, Paul. O atlântico negro: modernidade e dupla consciência. São Paulo: 2012.

GUERREIRO, Goli. Terceira diáspora: culturas negras no mundo atlântico. Salvador: Ed.

Corrupio, 2010. 
HALL, Stuart. Da Diáspora: Identidades e mediações culturais. Belo Horizonte: UFMG, Representações da UNESCO no Brasil, 2003.

MACHADO, Sara Abreu da Mata. Baobá na encruzilhada: ancestralidade, Capoeira Angola e permacultura. Tese de Doutorado defendida no programa de Doutorado Multidisciplinar e Multi-Institucional em Difusão do Conhecimento da UFBA/Faced. Salvador: UFBA, 2016.

MAGALHÃES FILHO, Paulo Andrade. Jogo de discursos: a disputa por hegemonia na tradição da capoeira angola. Salvador: EDFUBA, 2012.

MOREIRA, Nubia Regina. O feminismo negro brasileiro: um estudo do movimento de mulheres negras no Rio de Janeiro e São Paulo. Campinas: [s.n.], 2007.

OLIVEIRA, Josivaldo Pires de; LEAL, Luiz Augusto Pinheiro. Capoeira, identidade e gênero: ensaios sobre a história social da capoeira no Brasil. Salvador: EDFBA, 2009.

PERROT, Michelle. Os excluídos da História: operários, mulheres e prisioneiros. $7^{\text {a }}$ ed. Rio de Janeiro/São Paulo: Paz e terra, 2017.

REGO, Waldeloir. Capoeira Angola: ensaio sócio-etnográfico. Salvador: Editora Itapoan, 1968.

REIS, Leticia Vidor de Sousa. O mundo de pernas para o ar: capoeira no Brasil. São Paulo: Publisher Brasil, 1997.

RIBEIRO, Djamila. O que é lugar de fala? Série Feminismos plurais. Belo Horizonte: Letramento/Justificando, 2017.

SAFFIOTI, Heleieth. Gênero, patriarcado e violência. $2^{\mathrm{a}}$ ed. São Paulo: Expressão popular/ Fundação Perseu Abramo, 2015.

SANSONE, Livio. Negritude sem etnicidade: o local e o global nas relações raciais e na produção cultural negra do Brasil. Tradução de Vera Ribeiro. Salvador: EDUFBA/Pallas, 2007.

SCALDAFERRI, S.B.D. Nas vortá que o mundo deu, nas vortá que o mundo dá. Salvador: Programa de Pós-Graduação em Educação/UFBA, 2009.

SCHAWARCZ, Lilian Mortiz. O espetáculo das raças: cientistas, instituições e questão racial no Brasil- 1870- 1930. São Paulo: Companhia das letras, 1993. 12a reimpressão, 2014.

SCHWARCZ, Lilia. Nem preto, nem branco, muito pelo contrário: cor e raça na sociabilidade brasileira. $1^{\mathrm{a}}$ ed. São Paulo: Claro enigma, 2012.

SODRÉ, Muniz. A verdade seduzida. $3^{\mathrm{a}}$ ed. Rio de Janeiro: DP\&A, 2005.

SOMERLATE BARBOSA, Maria José. Capoeira: a gramática do corpo e a dança das palavras. Luso-Brazilian Review. Volume 42, Number 1, 2005. University of Wisconsin Press. Disponível em http://cppa.com.br/attachments/File/Artigos/18230806.pdf. Acesso em 16 mar. 2016.

VASSALO, Simone Ponde. A capoeira como patrimônio imaterial: novos desafios simbólicos e políticos. $32^{\circ}$ Encontro Anual da Anpocs. GT 29: Patrimônios, museus e ciências sociais. Disponível em: https://www.anpocs.com/index.php/papers-32-encontro/gt-27/gt298/2581-simonevassalo-a-capoeira/file. Acesso em: 21 set. 2015.

ZONZON, Christiane Nicole. Nas rodas de capoeira e da vida: corpo, experiência e tradição. Salvador: EDUFBA, 2017. 